\title{
Comparison of the adsorptive action of hydrotalcite, Moringa oleifera and activated carbon in the treatment of landfill leachate
}

\author{
Nair Conde de Almeida*, Valdenilson José Alves de Oliveira, \\ Dejanira de Franceschi de Angelis \\ Department of Biochemistry and Microbiology, Institute of Biosciences, São Paulo State University, UNESP, Av. 24A, no. 1515, \\ Bela Vista, CEP 13506-900, Rio Claro, São Paulo, Brazil, Tel. 5519 35264184; emails: nairca2015@gmail.com (N.C. de Almeida), \\ zito@rc.unesp.br (V.J.A. de Oliveira), dangelis@rc.unesp.br (D.F. de Angelis)
}

Received 14 February 2017; Accepted 6 September 2017

\begin{abstract}
Landfill leachate is formed by organic and inorganic toxic compounds. It has high salt concentration and pathogenic organisms that can cause environmental harm. Hydrotalcite, activated carbon and Moringa oleifera seeds have been used for the adsorption of contaminants and the purification of water. In the present study, landfill leachate was submitted to physicochemical and microbiological analysis before and after treatment with these adsorbents. The characterization of the leachate revealed a small number of heterotrophic bacteria and fungi. Total coliforms and Escherichia coli reached mean values of 17,900 and $890 \mathrm{NMP} / 100 \mathrm{~mL}$, respectively. The physicochemical analysis indicated high conductivity, color, turbidity, chemical oxygen demand (COD), biochemical oxygen demand in $5 \mathrm{~d}$, ammonia, boron, sodium and chlorides. Treatment with hydrotalcite produced the best results regarding the improvement in these variables, but led to an increase in $\mathrm{pH}$. Reused hydrotalcite $(\mathrm{Hr})$ provided reasonable results, but with less efficiency than hydrotalcite. Moreover, $\mathrm{Hr}$ failed to remove boron and aluminum and magnesium levels increased. In addition, $4 \%$ activated carbon (AC4\%) obtained better results regarding color and $\mathrm{COD}$, but failed to remove boron and ammonia efficiently and $1 \%$ activated carbon achieved similar results to AC4\%, but with lower degrees of removal. M. oleifera seed and extract achieved unsatisfactory results. All adsorbents, except M. oleifera extract, decreased the amount of heterotrophic bacteria approximately 10 -fold. Total coliforms and E. coli did not resist the treatments. None of the adsorbents removed sodium, chloride or the toxicity of the leachate.
\end{abstract}

A B S T R A C T

Keywords: Landfill leachate; Boron adsorption; Hydrotalcite; Moringa oleifera; Activated carbon

\footnotetext{
* Corresponding author.
} 